\title{
Desenvolvimento de bolo funcional isento de lactose e sacarose
}

\author{
Functional cake development free of lactose and sacarose \\ Desarrollo de pastel funcional exento de lactosa y sacarosis
}

Cláudia Nunes da Silva ${ }^{1 *}$, Débora Thaís Sampaio da Silva², Regilda Saraiva dos Reis MoreiraAraújo².

\section{RESUMO}

Objetivo: Elaborar e analisar a composição físico-química e sensorial de um bolo funcional isento de lactose e sacarose. Métodos: Trata-se de uma pesquisa experimental com delineamento transversal de abordagem quantitativa. Para verificar aceitação se aplicou os testes de escala hedônica e intenção de compra com 118 indivíduos, de ambos os sexos e idade entre 15 a 87 anos. As análises da composição físico-química foram realizadas no laboratório de Bromatologia e Bioquímica de Alimentos do Departamento de Nutrição da Universidade Federal do Piauí. A Análise Descritiva Quantitativa foi processada por 6 assessores treinados. Os dados obtidos foram analisados por estatística com auxílio do software SPSS versão 17. O estudo foi aprovado por Comitê de Ética em Pesquisa Resultados: A formulação obteve boa aceitação e 102 assessores não treinados informaram que comprariam o produto. O bolo apresentou $38,21 \%$ de umidade, $1,79 \%$ de teor de cinzas, $4,25 \%$ de proteínas, $32,01 \%$ de lipídeos, $23,67 \%$ de carboidratos e 399,86 $\mathrm{kcal} / 100 \mathrm{~g}$. Observou-se que os atributos sensoriais como aroma, sabor, textura, dureza, cor e aeração foram semelhantes aos bolos convencionais. Conclusão: Portanto, é possível desenvolver produtos com ótima aceitação, nutritivo e funcional, para atender necessidades de pacientes intolerantes à lactose e diabéticos.

Palavras-chave: Bolo, Composição Centesimal, Intolerância à Lactose.

\begin{abstract}
Objective: Elaborate and analyze the physical-chemical and sensorial composition of a functional cake free from lactose and sucrose. Methods: This is an experimental research with a cross-sectional and a quantitative approach. To verify acceptance, hedonic scale and intention to purchase tests were applied with 118 individuals of both sexes with age between 15 and 87 years. The analyzes of the physico-chemical composition were carried out in the Laboratory of Bromatology and Food Biochemistry of the Nutrition Department of the Federal University of Piaui. The Quantitative Descriptive Analysis was processed by 6 trained assessors. The data obtained were analyzed by statistical analysis through SPSS software version 17 . The study was approved by the Research Ethics Committee Results: The formulation was well accepted and 102 testers were ready for the acquisition. The cake presented $38.21 \%$ humidity, $1.79 \%$ ash content, $4.25 \%$ protein, $32.01 \%$ lipids, $23.67 \%$ carbohydrates and $399.86 \mathrm{kcal} / 100 \mathrm{~g}$. It was observed that the sensorial attributes such as aroma, flavor, texture, hardness, color and aeration were similar to conventional cakes Conclusion: Therefore, it is possible to develop products with optimal, nutritional and functional acceptance, to order to meet the needs of lactose intolerant patients and diabetics.
\end{abstract}

Keywords: Cake, Centesimal Composition, Lactose Intolerance.

\section{RESUMEN}

Objetivo: Elaborar y analizar la composición fisicoquímica y sensorial de un pastel funcional exento de lactosa y sacarosa. Métodos: Se trata de una investigación experimental con delineamiento transversal de abordaje cuantitativo. Para verificar la aceptación se aplicaron la escala hedónica y la intención de comprar pruebas con 118 individuos, de ambos sexos y edad entre 15 a 87 años. Los análisis de la composición fisicoquímica se realizaron en el laboratorio de Bromatología y Bioquímica de Alimentos del Departamento de Nutrición de la Universidad Federal de Piauí. El análisis descriptivo cuantitativo fue procesado por 6 asesores entrenados. Los datos obtenidos analizados por estadística con ayuda del software SPSS versión 17. El estudio fue

${ }^{1}$ Centro Universitário Santo Agostinho- UNIFSA. Teresina- Piauí. *E-mail: nunespp@yahoo.com.br.

2 Universidade Federal do Piauí. Teresina- Piauí. 
aprobado por el Comité de Ética en Investigación Resultados: La formulación obtuvo buena aceptación y 102 probadores se dispusieron por la adquisición. El pastel presentó 38,21\% de humedad, 1,79\% de contenido de cenizas, 4,25\% de proteínas, 32,01\% de lípidos, $23,67 \%$ de carbohidratos y 399,86 kcal / 100g. Se observó que los atributos sensoriales como aroma, sabor, textura, dureza, color y aireación fueron similares a los pasteles convencionales Conclusión: Por lo tanto, es posible desarrollar productos con óptima aceptación, nutritiva y funcional, para atender necesidades de pacientes intolerantes a la lactosa y diabéticos.

Palabras clave: Pastel, Composición Centesimal, Intolerancia a la lactosa.

\section{INTRODUÇÃO}

A alimentação além de suprir as necessidades nutricionais básicas, busca promover e diminuir o risco de doenças. Visto que, no atual cenário os alimentos funcionais são nicho de mercado pela alta rentabilidade, funcionabilidade e busca constante pelos consumidores. (SILVA JB, et al., 2015).

Os alimentos denominados funcionais apresentam propriedades nutricionais que oferecem benefícios à saúde, uma vez que esses alimentos possuem compostos químicos de extrema importância para a funcionalidade do corpo, dentre estes podemos citar os flavonoides, ômega 3, carotenoides, probióticos, fibras e muitos outros (VIDAL AM, et al., 2012).

A Associação Brasileira de Massas Alimentícias de pães, bolos e produtos industrializados (AMBIMA) afirma que o consumo de bolos funcionais aumentou muito nos últimos anos, em faixas etárias diferentes. Em decorrência do elevado consumo de produtos de panificação, várias preparações com compostos bioativos têm sido desenvolvidas, como bolos, pães, biscoitos, muffins, cup cakes, haja vista, que as mesmas apresentam inúmeros benefícios para várias patologias (CHIARELI CA, et al., 2017).

É importante ressaltar que os benefícios dos alimentos funcionais vêm sendo estudado, sobretudo em relação a enfermidades como Alzheimer, diabetes, câncer e doenças intestinais. Entretanto, ainda assim com seus inúmeros efeitos benéficos ao indivíduo proveniente do consumo de alimentos funcionais, observa-se que o hábito alimentar dos cidadãos brasileiros não abrange o consumo desses alimentos em proporções satisfatórias (LUIZETTO EM, et al., 2015).

Segundo Poletto BO et al. (2015) as peculiaridades inerentes, as características nutricionais e a vasta diversidades de bolos que o mercado apresenta têm como intuito ofertar constituintes e nutrientes essenciais, além de facilitar o desenvolvimento de produtos alimentícios que podem ser consumidos por pessoas que manifestam algum tipo de alergia ou restrição alimentar.

A alimentação da população Brasileira sofreu uma transição com o aumento do consumo de produtos industrializados e redução de produtos naturais como cereais, raízes, tubérculos, leguminosas, contribuindo para o surgimento de doenças crônicas não transmissíveis dentre elas o diabetes e o aumento da prevalência de alergias alimentares (ROLIM DM, et al., 2015).

$\mathrm{Na}$ intolerância a lactose ocorre à diminuição parcial ou total da atividade da enzima lactase responsável pela hidrólise da lactose. Essa patologia é recorrente na população mundial se manifestando desde um simples mal-estar e distensão abdominal até um choque anafilático (ZYCHAR BC e OLIVEIRA BA, 2017).

O diabetes mellitus é uma doença metabólica decorrente da redução da ação e da secreção de insulina, caracterizando-se por um quadro de hiperglicemia. A incidência de diabetes no mundo é alarmante (GOMES MA, et al., 2015)

Desta forma é de suma importância o desenvolvimento de preparações que sejam atrativas, auxilie no tratamento com intuito de disponibilizar produtos naturais fontes de nutrientes e substâncias benéficas à saúde, como antioxidantes e fibras, que possa ser consumido com regularidade pela população e que atenda as restrições. Esse estudo tem como intuito contribuir para a expansão de novas pesquisas evidenciando a relevância acadêmica para a área de Alimentos e Nutrição. No que diz respeito à importância profissional, o tema abordado irá instigar o surgimento de novas pesquisas e discussões no campo da Nutrição enquanto ciência da saúde, somando conhecimentos a cerca da temática. 
O referente estudo teve como objetivo desenvolver um bolo funcional isento de lactose e sacarose, verificar a aceitação por meio dos testes da escala hedônica e intenção de compra.

\section{MÉTODOS}

Trata-se de um estudo experimental com delineamento transversal de abordagem quantitativa.

A formulação do bolo foi realizada no Laboratório de Desenvolvimento de Produtos e Análise Sensorial de Alimentos do Departamento de Nutrição da Universidade Federal do Piauí (UFPI), A priori obteve-se a farinha da semente da abóbora. A abóbora foi higienizada e sanitizada (solução de hipoclorito de sódio a 1\%/15 min). Em seguida, retirou-se as sementes, lavou, torrou e liquidificou em aparelho de modelo turbo premium L-1000 BI 12V, por cerca de 3 minutos e triturou-se em moinho de rotor modelo TE-651/2 por 2 min. Os ovos, o óleo, as bananas e as passas foram liquidificadas e reservadas. Em um recipiente plástico, misturou-se manualmente a aveia, a farinha da semente da abóbora e a massa liquidificada, por último o fermento, até obtenção de um creme homogêneo. Colocou-se em assadeira retangular $(30 \times 40 \mathrm{~cm})$ untada e polvilhada. Assado em forno modelo 4BC Mônaco BCOC/AA, pré-aquecido a $220^{\circ} \mathrm{C}$ por 30 minutos (Tabela 1).

Tabela 1 - Formulação do bolo funcional com semente de abóbora, isento de lactose, sacarose.

\begin{tabular}{lc}
\hline Ingredientes & Formulação \\
\hline F (\%) & \\
Farelo de aveia & $5-25$ \\
Ovos caipira & $7-30$ \\
Óleo de milho & $3-20$ \\
Banana nanica & $0-42$ \\
Semente de abóbora & $1-10$ \\
Uvas passas & $3-20$ \\
Fermento em pó & $1-5$ \\
Canela em pó & $0,1-1$ \\
\hline
\end{tabular}

Fonte: Dos autores, 2019.

A análise sensorial foi realizada aplicando-se a Escala Hedônica de 9 pontos e Intenção de compra de 5 pontos (DUTCOSKY SD, 2013). Utilizou-se para os testes amostras de $25 \mathrm{~g}$, com 118 indivíduos não treinados, de ambos os sexos, com idade entre 15 a 87 anos, no mês de outubro de 2018. Para Análise Descritiva Quantitativa, participaram 6 assessores do sexo feminino, treinados e utilizou-se uma escala de 9 $\mathrm{cm}$, como descritores: aroma, sabor, textura, cor/aparência, aeração e dureza, para caracterização sensorial do bolo.

As análises da composição físico-química foram realizadas no Laboratório de Bromatologia e Bioquímica de Alimentos do Departamento de Nutrição da UFPI, nos meses de novembro e dezembro de 2018. Foram determinados: o teor de umidade por secagem em estufa a $105^{\circ} \mathrm{C}$, as cinzas por incineração em mufla a $550^{\circ} \mathrm{C}$, proteínas pelo método de macro Kjeldahl, lipídeos utilizando extrator de Soxhlet, carboidratos por diferenciação, conforme metodologia estabelecida pela AOAC (Association of Official Analytical Chemists) (2005). E o valor energético total por meio de valores de conversão (WATT B e MERRILL AL, 1963).

Os dados estatísticos foram analisados no Programa SPSS, versão 17, 2015.Os resultados foram apresentados em formas de tabelas e figuras.

O projeto foi aprovado pelo Comitê de Ética em Pesquisa em Seres Humanos - CEP, da Universidade Federal do Piauí, sob no 750.942. 


\section{RESULTADOS E DISCUSSÃO}

Segundo ABIP - Associação Brasileira da Indústria e Panificação e Confeitaria. Serviço de apoio as Micros e pequenas Empresas (2009), os produtos de panificação e confeitaria são de grande valia na lista de compras dos brasileiros, ocupa a terceira colocação e representa, em média, 12\% do orçamento familiar voltados a alimentação, é de grande valia o desenvolvimento de produtos que atendam de forma completa os anseios da população em uma era onde a globalização influencia na busca de melhor qualidade de vida, como apresentado na Figura 1 o resultado do teste de escala hedônica do bolo funcional isento de lactose e sacarose, onde se obteve uma ótima aceitação $(83,05 \%)$, apresentando maior frequência de notas de aceitação, 9 "gostei muitíssimo", 8 "gostei muito", 7 "gostei regularmente" e 6 "gostei ligeiramente, totalizando $98(83,05 \%)$ dos assessores gostaram do bolo funcional isento de lactose e sacarose"; $11(9,32 \%)$ foram "indiferente" e $9(7,63 \%)$ desgostaram.

Figura 1 - Escala Hedônica do Bolo Funcional Isento de Lactose e Sacarose.

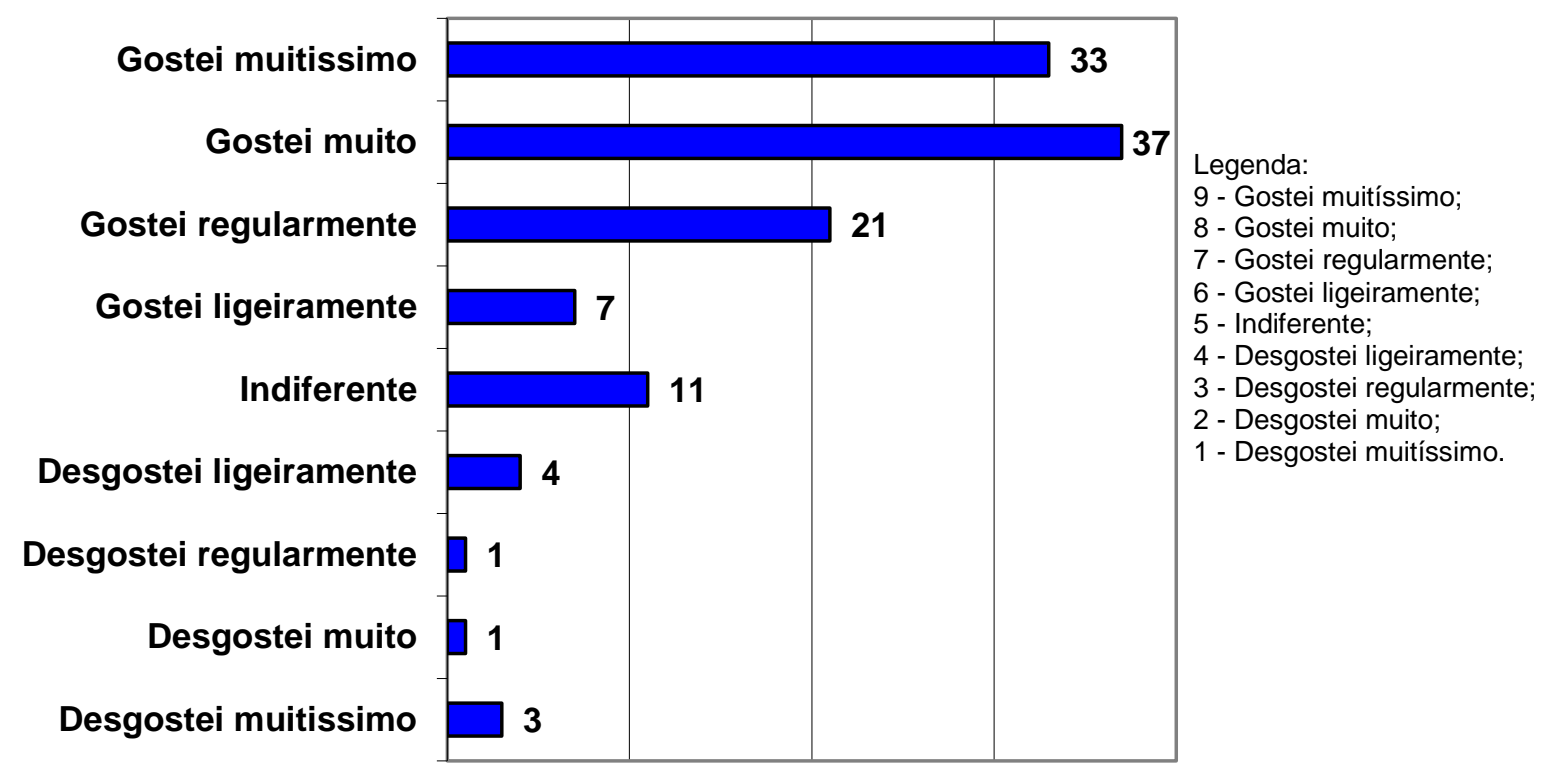

Fonte: Dos autores, 2019.

$\mathrm{Na}$ escala hedônica atingiu-se notas acima de 6. Esses resultados indicam ótima aceitação sensorial do bolo elaborado e uma boa opção para pessoas com restrições alimentares- diabéticos e intolerantes à lactose. Diferenciando-se pela qualidade nutricional e por possui propriedade funcional que previne o aparecimento de doenças ou auxiliam no seu tratamento, como: fibras, ácidos graxos essenciais, vitamina, minerais e outros.

No estudo de Chiareli CA et al. (2017) que avaliou um bolo funcional com chia observou-se uma aceitação semelhante de $95 \%$, nas junções das escalas $(9,8,7$ e 6$)$, quando comparados com o estudo em questão. Outros autores como Ozores B et al. (2015) elaboraram bolos com adição de 5\%, 10\% e 20\% da farinha do maracujá e conseguiram boa aceitação para os bolos com menor concentração da farinha, contrapondo-se quando o teor foi aumentado para $20 \%$ tendo diminuição significativamente, provavelmente devido ao sabor residual do maracujá. Já Silva e Benedetti (2018) desenvolveram um bolinho integral de aveia com recheio de brigadeiro de açaí, o qual apresentou aceitação $91 \%$ com repercussão favorável, semelhante a essa pesquisa.

Sabendo que os produtos de panificação encontram-se na lista de preferência de consumo da população, e o Brasil de acordo com instituto ECD - Consultoria Especializada em Food Service (2010) é o segundo país no ranking dos que mais consomem massas, a elaboração do bolo com a substituição da farinha de trigo pela 
aveia, o uso da semente da abóbora, óleo vegetal e frutas conferiram ao produto inúmeros benefícios por apresentar grande variedade de compostos bioativos como: flavonoides, ômega 3, carotenoides, probióticos, fibras solúveis e insolúveis, que são benéficos à saúde, prevenindo certas doenças como cardiovasculares, câncer de cólon, dislipidemias, e melhorando o funcionamento do organismo bem como elaborado por Frota KMG et al. (2010) que desenvolveram produtos de panificação (rocambole e biscoito) enriquecidos com farinha de feijão-caupi para melhorar o valor nutritivo destes produtos alimentícios, pois, além da maioria das formulações apresentar aceitação maior que 70\%, constatou-se um aumento da qualidade e quantidade de nutrientes, principalmente quanto ao teor de proteínas e, dos minerais, ferro, zinco, magnésio, potássio e da vitamina piridoxina.

O teste de intenção de compra revelou um grande potencial de mercado e intenção positiva de compra para o bolo funcional isento de lactose e sacarose, caso este realmente estivesse disponível no mercado,

A Figura 2 demonstra os resultados da intenção de compra, onde 102 (86,44\%) dos voluntários comprariam o bolo, cerca de $8(6,78 \%)$ " provalvelmente não compraria" e $3(2,54 \%)$ "não compraria".

Figura 2 - Intenção de Compra do Bolo Funcional Isento de Lactose e Sacarose.

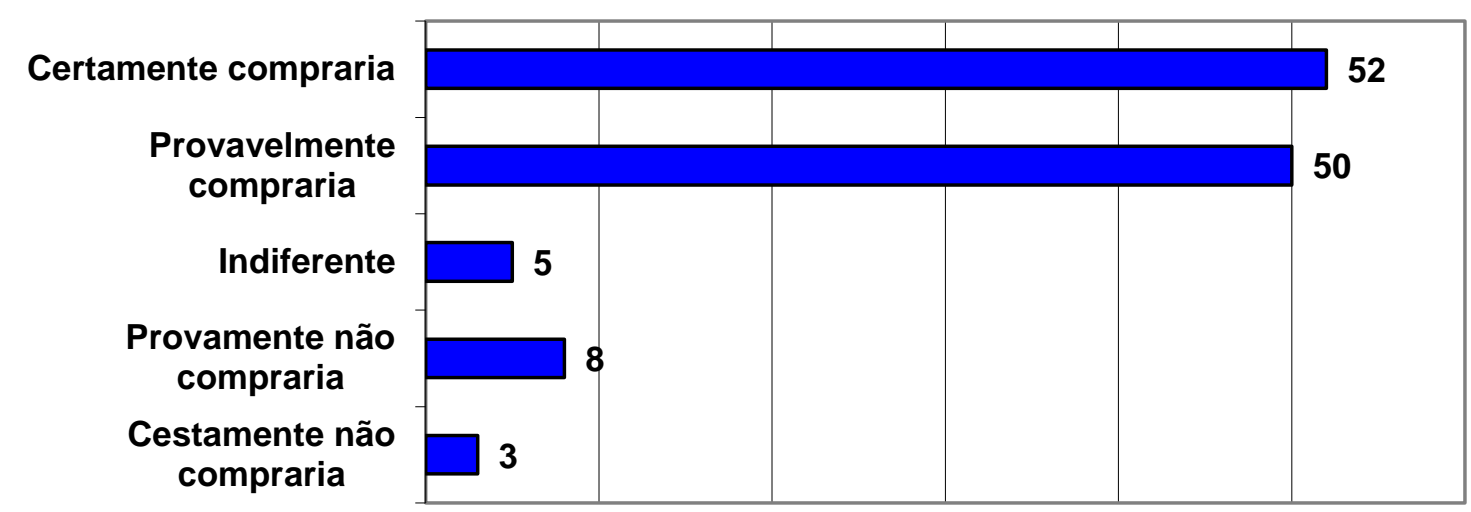

Fonte: Dos autores, 2019.

Andrade TA et al. (2015) elaboraram um bolo a partir de três formulações (F1), (F2) e (F3), enriquecido com farinha de soja e mix de 3 cereais (amaranto, aveia e quinoa), analisaram a intenção de compra e verificaram uma média de $70 \%$ para as formulações $\mathrm{F} 1$ e F2, cujo os provadores certamente comprariam, com intenção de compra menor do que a verificada neste estudo.

Baumgarten AC e Fassina $\mathrm{P}$ (2017) ao desenvolver um bolo de caneca funcional isento de glúten e lactose com uma amostra padrão e outra teste, constataram que a maioria dos participantes compraria tanto a amostra teste quanto a amostra padrão, alcançando maior preferência para a amostra padrão, 93,5\% ( $n=43$ ) quando comparado a amostra teste $(71,7 \%)(n=33)$.

A Tabela 2 apresenta os resultados de composição centesimal e valor energético do bolo em análise.

Tabela 2 - Composição Centesimal e Valor Energético Total do Bolo Funcional Isento de Lactose e Sacarose.

\begin{tabular}{lrr}
\hline Nutrientes $(\mathrm{g} / 100 \mathrm{~g}) /$ & Mesvio Padrão \\
VET $($ Kcal $)$ & 1,79 & 0,04 \\
\hline Cinzas & 38,21 & 0,50 \\
Umidade & 4,25 & 0,51 \\
Proteínas & 32,02 & 0,40 \\
Lipídeos & 23,67 & - \\
Carboidratos (Por diferença) & 399,86 & - \\
VET & & \\
\hline
\end{tabular}

Fonte: Dos autores, 2019. 
A fração "cinzas" representa as substâncias inorgânicas presentes no alimento. Quando um alimento é queimado a matéria orgânica é transformada permanecendo apenas os minerais presentes no alimento. Brito $\mathrm{O}$ et al. (2017) ao formular um bolo enriquecido com farinha de quiabo obtiveram o teor de cinzas de 1,82\% resultado semelhante a esse estudo onde o teor de cinzas foi de 1,79\%. Pereira HLS. (2014) avaliou a composição centesimal de bolo de chocolate isento de glúten e lactose fortificada com farinha de sementes de melão, observou-se que o conteúdo de cinzas foi de 1.32\%. Em outro estudo Silva JB et al. (2015) o teor de cinzas foi em torno de 3,80\% para o biscoito produzido com farinha de semente de abóbora.

A umidade é uma característica relacionada à estabilidade e qualidade de um alimento. $O$ bolo analisado possui umidade de 38,21\%. Segundo Agência Nacional de Vigilância Sanitária (2000) recomenda teores máximos de umidade para produtos de panificação à base de farinha de trigo até $38 \%$. Chiareli CA et al. (2017) determinaram teor de umidade de $33,49 \%$ no bolo de fibras solúveis enriquecido com chia. Moura KLA e Moura SAI. (2014) classificaram como umidade intermediária os teores de (20,0 a 40,0\%). Assim, a formulação elaborada apresenta boa preservação e baixo potencial de crescimento bacteriano.

Branco FRW. (2017), ao produzir bolos com farinha de maracujá com concentração de $10 \%$ a $15 \%$ substituindo a farinha de trigo, concluiu que a umidade do bolo em ambas girou em torno de $(28,95 \%)$ e $(30,16 \%)$ respectivamente, podendo ser explicado pela capacidade de retenção de água das fibras, esses teores encontram-se menores ao que foi obtido nesse estudo. Soares JP et al. (2018) elaborou um bolo com a proteína do soro do leite e sem adição de açúcar, no qual foi possível constatar a umidade em torno de $57,62 \%$.

No tocante as proteínas, o bolo exibiu uma porcentagem de $4,25 \%$, justificado pelos ingredientes da formulação ser preponderantemente de origem vegetal. Assim como nas formulações de Oliveira ESF et al. (2017), desenvolvidas com adição de farinha de bagaço de azeitona em bolos com goma xantana isentos de glúten, no qual obtiveram teores proteicos de 5,38\% (F1), 4,61\% (F2) e 4,78\% (F3). Já Farinelli BCF et al. (2014) elaboraram biscoito doce de casca de banana e o teor de proteínas foi $6,42 \%$.

O bolo elaborado apresentou $32,02 \%$ de lipídeos, porém ressalta-se a boa qualidade do perfil lipídico de monoinsaturados e poli-insaturados, provenientes do óleo de milho (ácido linoleico w-6) e da semente de abóbora (oleico w-9 e w-6). Freitas CJ et al. (2014) desenvolveram biscoitos confeccionados com farinha de semente de abóbora (FSA) e farinha de semente de baru (FSB) para celíacos, evidenciaram que o teor lipídico foi de $27,30 \%$ para a (FSA) e $26,37 \%$ (FSB). Resultados próximos aos obtidos no presente estudo.

Bitencourt $C$ et al. (2014) afirmaram que a quantia de lipídeos presentes no bolo enriquecido com a semente da abóbora são maiores quando comparados ao bolo tradicional à base de farinha de trigo. E esses resultados podem estar relacionados a quantidades de ácidos graxos monoinsaturados e poli-insaturados, presentes nas sementes, que por sua vez atuam na redução dos níveis de colesterol sanguíneo.

O bolo funcional apresentou $23,67 \%$ de carboidratos, importante salientar que esse macronutriente é de fundamental importância, pois é a fonte primária de energia para o corpo. O tipo de carboidratos é o diferencial pelo teor de fibras (betaglucana) presentes na aveia, banana, passas. Segundo informações disponibilizadas pela empresa PepsiCo do Brasil (Quaker), $40 \mathrm{~g}$ de farelo de aveia possui $3 \mathrm{~g}$ de fibras. No presente estudo utilizou-se $150 \mathrm{~g}$ de aveia aproximadamente $11,25 \mathrm{~g}$ de fibras. A Organização Mundial da Saúde recomenda que mais de $55 \%$ da energia ingeridas diariamente seja proveniente dos carboidratos. (SANGUINETTI MG, 2014). O Guia alimentar para população brasileira recomenda um consumo diário de $25 \mathrm{~g}$ de fibras (BRASIL, 2014). Na pesquisa Stavale MDO (2017) que desenvolveu um bolo tipo pound cake com polpa de maçã obteve $24,25 \%$ de carboidratos, dado semelhante ao obtido neste estudo.

Quanto ao valor calórico, constatou-se que o bolo contém em 100 gramas 399,86 Kcal. Valores próximos de calorias foram reportados por Carneiro GS et al. (2015), em estudo de caracterização físico-química de bolos com substituição parcial da farinha de trigo por aveia, quinoa e linhaça, nas formulações $F 1$ e F2, com 321,58 e $321,25 \mathrm{Kcal}$ respectivamente. Bitencourt $\mathrm{C}$ et al. (2014) ao desenvolver bolos enriquecidos usando semente de abóbora em diferentes concentrações, determinaram valor energético em torno de 393,92 e $401,68 \mathrm{kcal}$, resultados estes similares quando comparados com a presente pesquisa. 
Os atributos sensoriais e a intensidade foram definidos para realização da Análise Descritiva Quantitativa (ADQ), cujas médias encontram-se na Figura 3. No gráfico aranha os atributos sensoriais são representados do ponto zero da escala e a intensidade aumenta do centro para periferia.

A análise da formulação do bolo gerou uma boa avaliação para todos os atributos sensoriais analisados: a aeração alcançou média de 6,73 "bolo fofo", obteve média de 6,86 com intensidade para sabor banana com canela, com 6,01 prevaleceu aroma banana e canela, na cor/aparência acentua-se marrom granulado $(5,83)$ caracterizando os ingredientes aveia, passas e banana, no atributo textura a amostra se sobressaiu pela macieza, suculência, não esmigalhava $(1,2)$ e quanto a dureza estava adequada para bolo de 4,1 .

Figura 3 - Gráfico Aranha dos Atributos Sensoriais do Bolo Funcional Isento de Lactose e Sacarose.

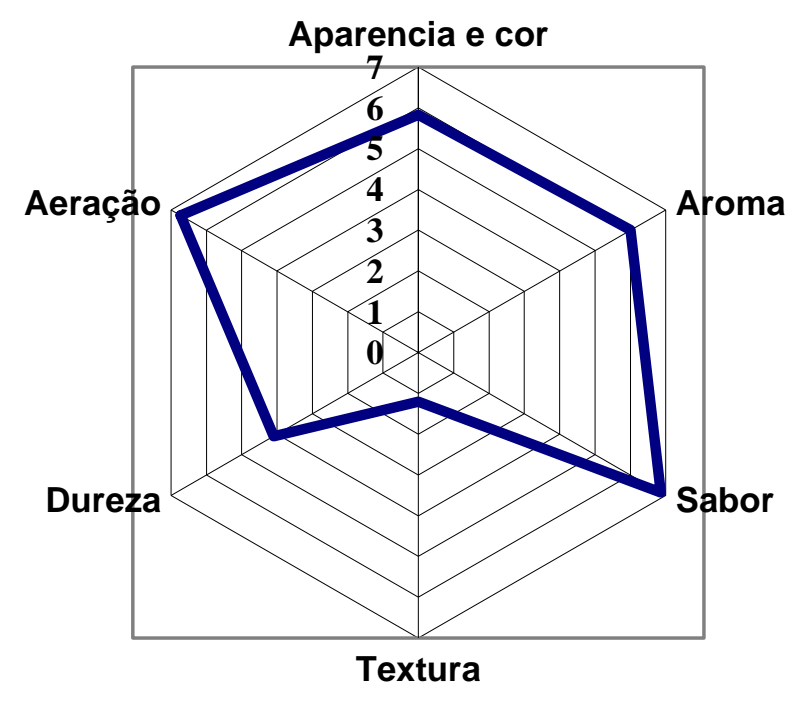

Fonte: Dos Autores, 2019.

Souza AG et al. (2014) obtiveram ótimas notas entre 8 e 9, para os atributos cor, aroma, textura, sabor (nota 6) e impressão global de muffins adicionados de castanha portuguesa. O aroma e sabor são respectivamente as características mais importantes e que interferem nas propriedades sensoriais dos produtos alimentícios desenvolvidos e produzidos com ingredientes diferenciados (CHIARELI CA, et al., 2017).

Atualmente, há um crescente interesse para o desenvolvimento de novos ingredientes e alimentos como veículo de promoção do bem-estar e saúde e, ao mesmo tempo, como prevenção e redução dos riscos de algumas doenças. Os alimentos enriquecidos são desenvolvidos a partir do crescente avanço de pesquisas científicas, relacionando alimentação e saúde buscando uma melhoria na qualidade de vida dos consumidores.

\section{CONCLUSÃO}

O bolo elaborado apresentou uma excelente aceitação e notória intenção de compra pelo público. As análises de cinzas, umidade, proteínas e lipídios demonstraram teores adequados para este tipo de produto. Além de possuir excelente valor calórico. Com relação aos atributos sensoriais os mesmos apresentaram ótimos resultados em todos os quesitos avaliados. Portanto, é possível desenvolver produto isento de lactose e sacarose realizando a substituição dos ingredientes padrão, por ingredientes que agreguem valor nutritivo, funcional e atendam as necessidades dos pacientes intolerantes e diabéticos, visando assim uma melhor qualidade da vida. 


\section{REFERÊNCIAS}

1. ANDRADE TA, et al. Processamento de bolo com farinha de soja e mix de flocos de aveia, quinoa e amaranto: estudo de aceitabilidade. Revista Brasileira de Produto Agroindustriais, 2015; 17(1): 25-31.

2. ABIP - Associação Brasileira da Indústria e Panificação e Confeitaria. Serviço de apoio as Micros e pequenas Empresas. A importância do pão do dia - encarte técnico 2009.

3. AOAC (Association of Official Analytical Chemists). Official methods of analysis, 16 ed. Arlington: AOAC, 2005.

4. BAUMGARTEN AC, FASSINA P. Análise sensorial de um bolo de caneca funcional isento de glúten e lactose. Revista Caderno Pedagógico, 2017; 12(2): 80-90.

5. BITENCOURT C, et al. Elaboração de Bolos Enriquecidos com Semente de Abóbora: Avaliação Química, Física e Sensorial. Revista B.CEPPA, 2014; 32(1): 19-32.

6. BRANCO FRW. Desenvolvimento de bolo com substituição parcial da farinha de trigo por farinha obtida a partir do subproduto de maracujá. Monografia (Bacharel em Nutrição) - Universidade Federal de Mato Grosso, Cuiabá, 2017; 44p.

7. BRASIL. Ministério da Saúde. Agência Nacional de Vigilância Sanitária. Resolução RDC no 90: Regulamento técnico para fixação de identidade e qualidade de pão. Brasília, 2000.

8. BRITO O, et al. Aceitabilidade e características tecnológicas de bolo enriquecido com farinha de maracujá. Revista Ciências da Saúde, 2015; 16(1): 61-69.

9. CARNEIRO GS, et al. Caracterização Físico-Química de Bolos com Substituição Parcial da Farinha de Trigo por Aveia, Quinoa e Linhaça. Enciclopédia Biosfera Centro Científico Conhecer, 2015; 11(21): 33-49.

10. CHIARELI CA, et al. Desenvolvimento de um bolo rico em fibras solúveis enriquecido com chia. Revista Ciências Nutricionais Online, 2017; 1(1): 46-52.

11. DUTCOSKY SD. Análise Sensorial de Alimentos. 4. ed. Curitiba: Champagnat, 2013; 513p.

12. ECD - Consultoria Especializada em Food Service, 2010.

13. FARINELLI BCF, et al. Elaboração, Análise Sensorial e Características Fisico-Químicas do Biscoito Doce de Casca de Banana. Revista Ensaios Ciências: Ciências Biológicas, Agrárias e Saúde, 2015; 18(2): 77-82.

14. FREITAS CJ, et al. Caracterização física, química e sensorial de biscoitos confeccionados com farinha de semente de abóbora (FSA) e farinha de semente de baru (FSB) para celíacos. Revista Demetra: Alimentação, Nutrição e Saúde, 2014; 9(4): 1003-1018.

15. FROTA KMG, et al. Utilização da farinha de feijão-caupi (Vignaunguiculata (L.) Walp) na elaboração de produtos de panificação. Ciência e Tecnologia de Alimentos, 2010; 30(1); 44-50.

16. GOMES MA, et al. Alimentação e Diabetes Mellitus: Percepção e Consumo Alimentar de Idosos no Interior de Pernambuco. Revista Brasileira Promoção e Saúde, 2015; 28(3): 370-378.

17. LUIZETTO EM, et al. Alimentos funcionais em alimentação coletiva: reflexões acerca da promoção da saúde fora do domicílio. Revista Nutrire, 2015; 40(2); 188-199.

18. MOURA KLA, MOURA SIA. Desenvolvimento e avaliação das características nutricionais, físico-químicas e sensoriais de bolo com diferentes tipos de farinhas e castanha-do-brasil. Monografia (Bacharelado em Engenharia de Alimentos) - Universidade Federal de Rondônia, Ariquemes, 2014;67p.

19. OLIVEIRA ESF, et al. Adição de farinha de bagaço de azeitona em bolos com goma xantana isentos de glúten. IX Salão Internacional de Ensino, Pesquisa e Extensão, novembro de 2017.

20. OZORES B, et al. Aceitabilidade e características tecnológicas de bolo enriquecido com farinha de maracujá. Revista Ciências da Saúde, 2015; 16(1): 61-69.

21. PEREIRA, H. L. S. Aceitabilidade e composição centesimal de bolo de chocolate (tipo mãe benta) isento de glúten e lactose fortificada com farinha de sementes de melão (Cucumis melo). Monografia (Bacharelado em Nutrição) Universidade Federal do Maranhão, São Luís, 2014; 51p.

22. POLETTO BO, et al. Avaliação Físico-Química de Bolo de Chocolate Modificado. Revista Científica da Faculdade de Educação e Meio Ambiente, 2015; 6(2): 77-91.

23. ROLIM DM, et al. Avaliação do SISVAN na gestão de ações de alimentação e nutrição em Minas Gerais, Brasil. Revista Ciência Saúde Coletiva, 2015; 20(8): 2359-2369.

24. SANGUINETTI MG. Análise da Composição Físico-Química e Sensorial de Bolos Elaborados com Farinha de Arroz e de Banana Verde. Monografia (Bacharelado em Nutrição) - Universidade Federal do Rio Grande do Sul, Porto Alegre, 2014; 44p.

25. SILVA JB, et al. Biscoitos Enriquecidos com Farinha de Semente de Abóbora como Fonte de Fibra Alimentar. Revista Destaques Acadêmicos, 2015; 7(4): 174-184.

26. SILVA PRA, BENEDETTI PCD. Desenvolvimento e aceitação de bolinho integral de aveia com recheio de brigadeiro de açaí. Revista União das Faculdades dos Grandes Lagos, 2018; 1(1): 1-9.

27. SOARES JP. Efeito da adição de proteína do soro do leite como substituto do trigo na formulação de bolos sem adição de açúcar. Brazilian Journal of Food Technology, 2018; 21: 1-9.

28. SOUZA AG, et al. Propriedades nutricionais da castanha portuguesa (Castanea sativa Mill) e elaboração de produtos. Cadernos da Escola de Saúde, 2014; 2(12): 109-124.

29. STAVALE MDO Desenvolvimento de bolo tipo pound cake com polpa de maçã. Monografia (Especialista em gestão da produção de refeições saudáveis) - Universidade Federal de Brasília, 2017; 64p.

30. VIDAL AM, et al. Ingestão de Alimentos Funcionais e sua contribuição para diminuição da Incidência de doenças. Caderno de Graduação - Ciências Biológicas e da Saúde, 2012; 1(1): 43-52.

31. ZYCHAR BC, OLIVEIRA BA. Fatores Desencadeantes da Intolerância á Lactose: Metabolismo Enzimático, Diagnóstico e Tratamento. Revista Atas de Ciências da Saúde, 2017; 5(1): 35-46. 